\title{
Proton and deuteron activation measurements at the NPI and future plans in SPIRAL2/NFS
}

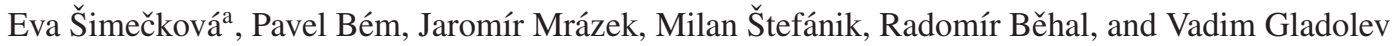 \\ Nuclear Physics Institute, CAS, 25068 Řež, Czech Republic
}

\begin{abstract}
The proton- and deuteron-induced reactions are of a great interest for the assessment of induced radioactivity of accelerator components, target and beam stoppers as well as isotope production for medicine. In the present work, the deuteron-induced reaction cross sections on zinc were investigated by stacked-foil activation technique with deuteron beam of $20 \mathrm{MeV}$ energy from the cyclotron U-120M of NPI CAS Rež. Also the proton activation cross section measurement of iron is presented. The comparison of present results to data of other authors and to predictions of evaluated data libraries is discussed. The investigation shall continue for higher proton and deuteron energy interval 20-35 MeV at SPIRAL2/NFS facility using a charged particle irradiation chamber with pneumatic transport system to measure isotopes and isomers with half-lives in minutes-regions.
\end{abstract}

\section{Introduction}

The proton- and deuteron-induced activations have a great interest for the assessment of induced radioactivity in the accelerator components, targets and beam stoppers as well as isotope production for medicine. Moreover, description of deuteron-nucleus interaction represents actually an important test of the reaction mechanism models, because of the weak deuteron binding energy of $2.224 \mathrm{MeV}$ [1].

We report cross section measurements of natural $\mathrm{Zn}$ and $\mathrm{Fe}$ by $\mathrm{d}$ and $\mathrm{p}$, respectively. The radioisotopes ${ }^{67,66} \mathrm{Ga}$, ${ }^{61,64} \mathrm{Cu}$ produced by deuteron activation of zinc isotopes are widely used in nuclear medicine. Iron belongs to main important constructing material.

The irradiation was carried out on CANAM [2] infrastructure of NPI CAS using a deuteron/proton beam of the variable-energy cyclotron U-120M operating in the negative-ion mode.

\section{Experiment}

\subsection{Experimental set-up}

We measured the cross sections deuteron-induced reaction on natural zinc and proton induced reaction on natural iron by stacked-foil technique. High purity Zn or Fe foils interleaved with aluminium monitors were placed in a cooled reaction chamber that serves also as a Faraday cup and were impinged by collimated deuteron or proton beam. The high purity $\mathrm{Zn}$, Fe (Goodfeloow product, 99.99\% and $99.5 \%$ purity, $25 \mu \mathrm{m}$ declared thickness) and $\mathrm{Al}(50 \mu \mathrm{m}$ declared thickness) were weighed to avoid relatively large uncertainties in the foil thickness declared by producer. Duration of deuteron activation was $10.35 \mathrm{~min}$ with $0.328 \mu \mathrm{A}$ mean current and duration of proton irradiation was 27 min with mean beam current $0.292 \mu \mathrm{A}$.

a e-mail: simeckova@ujf.cas.cz
After several minutes the activities of the irradiated foils were measured by two calibrated HPGe detectors of $50 \%$ efficiency and of FWHM $1.8 \mathrm{keV}$ at $1.3 \mathrm{MeV}$. The computers registering beam current and sample activities were time synchronized.

\subsection{Data analysis}

The energy of reaction in subsequent foils was calculated by using SRIM 2009 [3] code taking into account the initial deuteron energy $20.0 \mathrm{MeV}$ and the proton energy $20.1 \mathrm{MeV}$

The gamma-rays from irradiated samples were measured with HPGe detectors. Activated isotopes were identified on the basis of $\mathrm{T}_{1 / 2}, \quad \gamma$-ray energies and intensities [4]. The measured activities were corrected for decay during and after the irradiation.

Measured errors consist of statistical error of peak determination and systematic errors of current certainty $(5 \%)$, uncertainty of foil thickness (2\%) and detector efficiency uncertainty (2\%). The uncertainty of initial beam energy determination is $1 \%$ and beam energy spread is $1.8 \%$.

\section{Results}

\section{1. $d+Z n$}

The natural zinc contains ${ }^{64} \mathrm{Zn}(48.27 \%),{ }^{66} \mathrm{Zn}(27.97 \%)$, ${ }^{67} \mathrm{Zn}(4.10 \%),{ }^{68} \mathrm{Zn}(19.02 \%)$ and ${ }^{70} \mathrm{Zn}(0.63 \%)$. The present data are shown in Figs. 1-10 in comparison with EXFOR database [5-17] data and with evaluated data from the EAF 2007 [18] and TENDL 2014 [19] libraries. All evaluated data are corrected/normalized to the natural abundance of the sample.

The reaction ${ }^{68} \mathrm{Zn}(\mathrm{d}, 2 \mathrm{n})$ is the main contributor to ${ }^{68} \mathrm{Ga}$ production in the region up to $20 \mathrm{MeV}$. Present data (Fig. 1) are in rough agreement with the data of Gilly [17] (they

(C) The Authors, published by EDP Sciences. This is an Open Access article distributed under the terms of the Creative Commons Attribution License 4.0 (http://creativecommons.org/licenses/by/4.0/). 


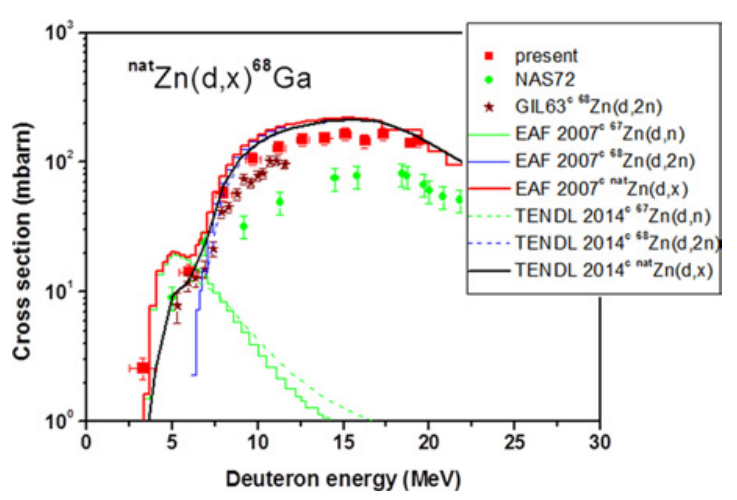

Figure 1. ${ }^{\text {nat }} \mathrm{Zn}(\mathrm{d}, \mathrm{x}){ }^{68} \mathrm{Ga}$ production cross section vs. deuteron energy.

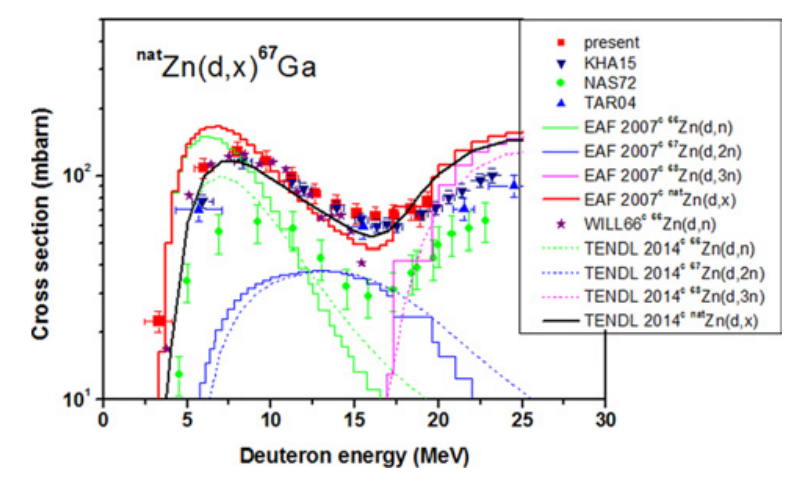

Figure 2. ${ }^{\text {nat }} \mathrm{Zn}(\mathrm{d}, \mathrm{x}){ }^{67} \mathrm{Ga}$ production cross section vs. deuteron energy.

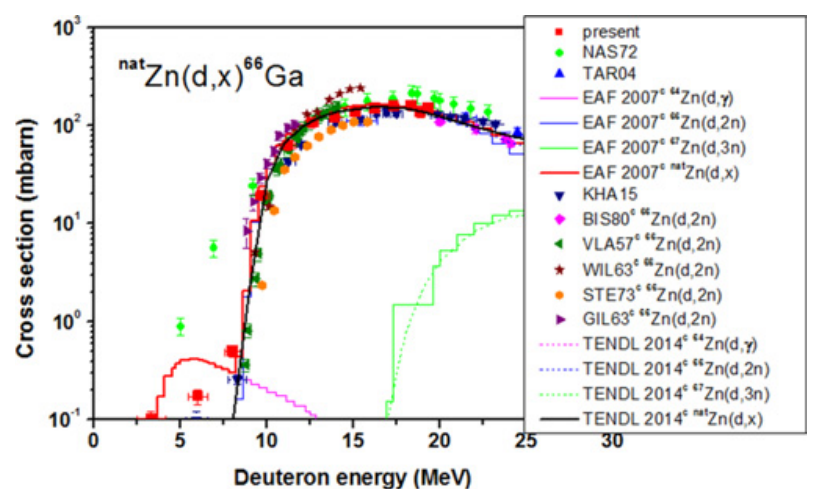

Figure 3. ${ }^{\text {nat }} \mathrm{Zn}(\mathrm{d}, \mathrm{x})^{66} \mathrm{Ga}$ production cross section vs. deuteron energy.

measured only the $(\mathrm{d}, 2 \mathrm{n})$ reaction) while Nassiff [8] data are significantly lower. It is seen that while the TENDL 2014 library describes low energy part reasonably, EAF 2007 exhibits a bump, that comes from overestimation of the small contribution of the ${ }^{64} \mathrm{Zn}(\mathrm{d}, \mathrm{n})$ reaction.

Similar case is ${ }^{67} \mathrm{Ga}$ production reaction (Fig. 2). Present are in agreement with previous authors except Nassiff [8]. There are competitive reactions ${ }^{66} \mathrm{Zn}(\mathrm{d}, \mathrm{n})$ and ${ }^{67} \mathrm{Zn}(\mathrm{d}, 2 \mathrm{n})$ in the region up to $20 \mathrm{MeV}$. The TENDL 2014 library describes experimental values while the EAF 2007 library overestimates contribution of the $(\mathrm{d}, \mathrm{n})$ reaction.

Excitation function for the ${ }^{\text {nat }} \mathrm{Zn}(\mathrm{d}, \mathrm{x})^{66} \mathrm{Ga}$ is shown in Fig. 3. TENDL 2014 agrees with present data. Both the evaluated libraries describe $(\mathrm{d}, 2 \mathrm{n})$ reaction, but EAF 2007 overestimates the small contribution of ${ }^{64} \mathrm{Zn}(\mathrm{d}, \gamma)$ reaction.

The main reaction producing ${ }^{65} \mathrm{Ga}$ is ${ }^{64} \mathrm{Zn}(\mathrm{d}, \mathrm{n})$ in this energy region (Fig. 4). Present data are in only rough

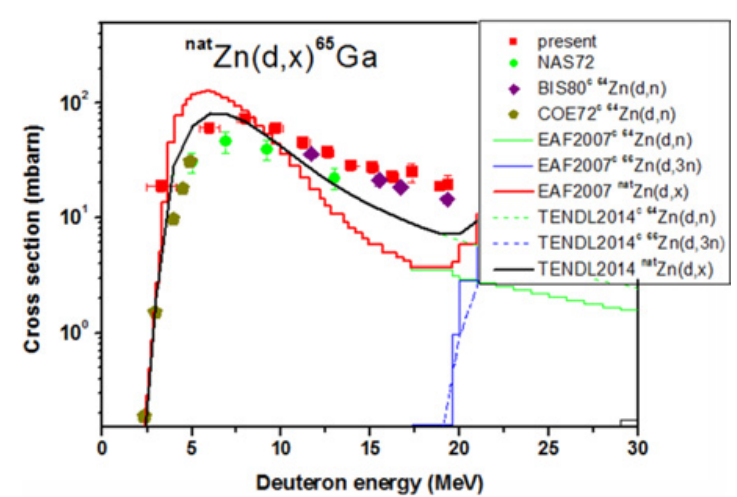

Figure 4. ${ }^{\text {nat }} \mathrm{Zn}(\mathrm{d}, \mathrm{x})^{65} \mathrm{Ga}$ production cross section vs. deuteron energy.

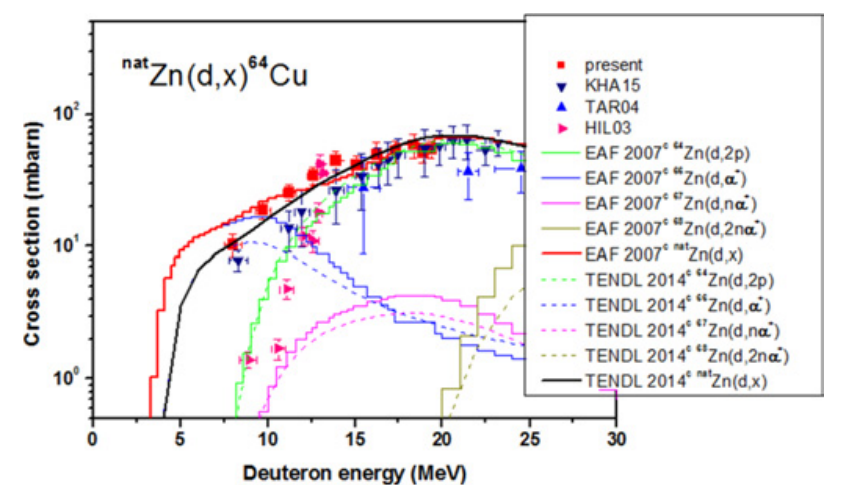

Figure 5. ${ }^{\text {nat }} \mathrm{Zn}(\mathrm{d}, \mathrm{x}){ }^{64} \mathrm{Cu}$ production cross section vs. deuteron energy.

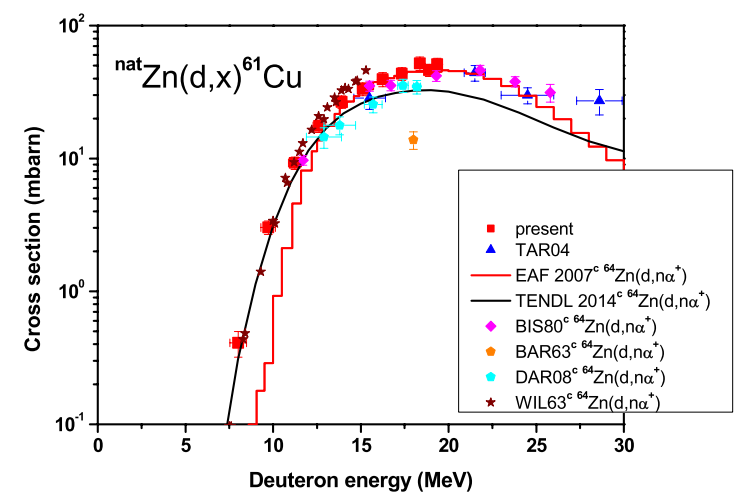

Figure 6. ${ }^{\text {nat }} \mathrm{Zn}(\mathrm{d}, \mathrm{x})^{61} \mathrm{Cu}$ production cross section vs. deuteron energy.

agreement with previous measurements and also with both evaluated libraries. The picture also shows that the TENDL 2014 library describes the excitation function better than the EAF 2007 one.

At least three stable isotopes of $\mathrm{Zn}$ compete in ${ }^{64} \mathrm{Cu}$ production. The experimental data are contradictory at low energies. However the TENDL 2014 library agrees with present experimental data (Fig. 5).

Only reaction ${ }^{64} \mathrm{Zn}\left(\mathrm{d}, \mathrm{n} \alpha^{+}\right)$produces ${ }^{61} \mathrm{Cu}$ isotope. Neither library describes experimental data accurately (Fig. 6).

Only ${ }^{70} \mathrm{Zn}(\mathrm{d}, \mathrm{p})$ reaction produces ${ }^{71 m} \mathrm{Zn}$ isotope. Neither library agrees with experimental data, nevertheless TENDL 2014 describes the excitation function shape better (Fig. 7). 


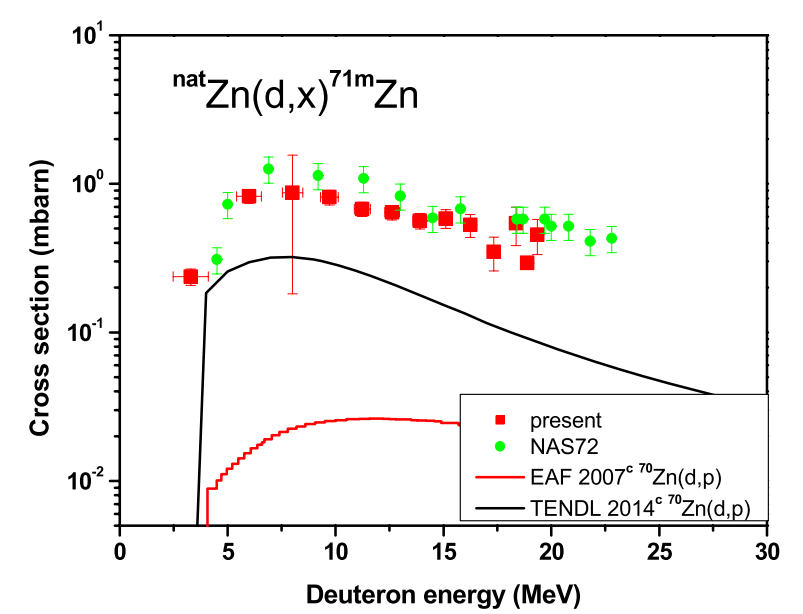

Figure 7. ${ }^{\text {nat }} \mathrm{Zn}(\mathrm{d}, \mathrm{x})^{71 m} \mathrm{Zn}$ production cross section vs. deuteron energy.

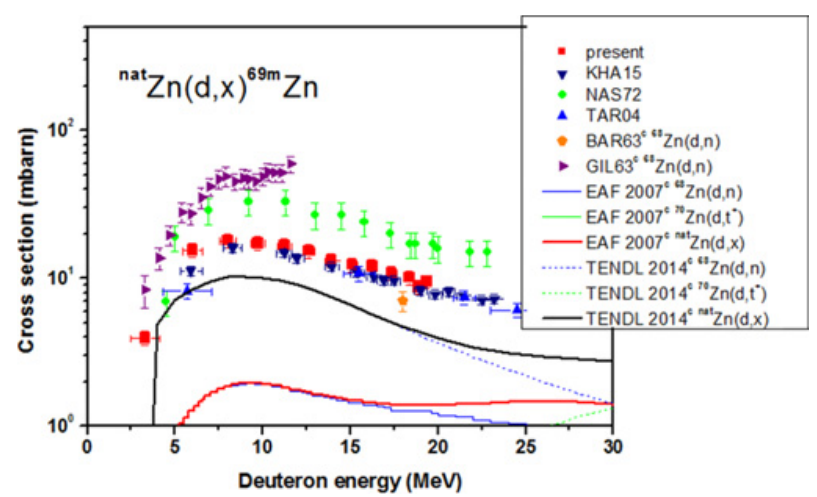

Figure 8. ${ }^{\text {nat }} \mathrm{Zn}(\mathrm{d}, \mathrm{x})^{69 m} \mathrm{Zn}$ production cross section vs. deuteron energy.

The ${ }^{68} \mathrm{Zn}(\mathrm{d}, \mathrm{p})$ is main reaction that produces ${ }^{69 m} \mathrm{Zn}$ in region up to $20 \mathrm{MeV}$. It is seen from Fig. 8. that present data are in agreement with data Khandaher [5] and Tarkanyi [6], but Nassiff [8] and Gilly [17] experimental points are too high. Neither library agrees with the experimental data as in previous case.

The present data of ${ }^{65} \mathrm{Zn}$ production are in satisfactory agreement with data of previous authors (Fig. 9), except too small data by Nassiff [8]. The main contributory reaction is ${ }^{64} \mathrm{Zn}(\mathrm{d}, \mathrm{p})$ for which the evaluated libraries predictions are too low.

Only the single ${ }^{64} \mathrm{Zn}\left(\mathrm{d}, \mathrm{t}^{+}\right)$generates ${ }^{63} \mathrm{Zn}$ isotope (Fig. 10). Present data are compatible with previous measurement of Bissem [10]. The TENDL 2014 library has a worse agreement with experimental data at low energies than EAF 2007.

\section{2. $p+F e$}

The natural iron contains ${ }^{54} \mathrm{Fe}(5.85 \%),{ }^{56} \mathrm{Fe}(91.85 \%)$, ${ }^{57} \mathrm{Fe}(2.12 \%)$, and ${ }^{58} \mathrm{Fe}(0.28 \%)$. We have obtained experimental data for the production of ${ }^{52 m, 52,54,56} \mathrm{Mn}$ and $55,56,57,58(m+g)$ Co from proton induced reaction on natural iron. The data are in agreement with majority of previous works and with the TENDL 2014 and EAF 2007 libraries.

We observed also $\gamma$-lines from decay of ${ }^{51} \mathrm{Cr}$. However the threshold of the first possible reaction ${ }^{56} \mathrm{Fe}(\mathrm{p}, \mathrm{d} \alpha)$ is $17.74 \mathrm{MeV}$ thus we ascribed the production of ${ }^{51} \mathrm{Cr}$ nuclei to the decay of ${ }^{51} \mathrm{Mn}$ generated in the reaction

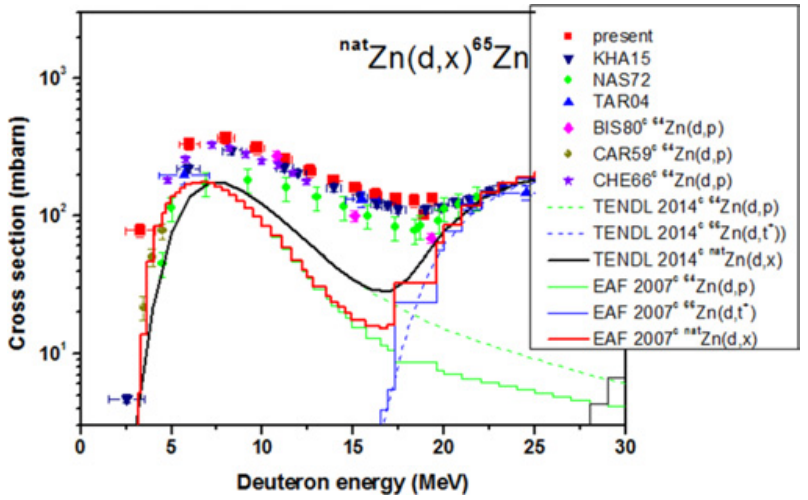

Figure 9. ${ }^{\text {nat }} \mathrm{Zn}(\mathrm{d}, \mathrm{x})^{65} \mathrm{Zn}$ production cross section vs. deuteron energy.

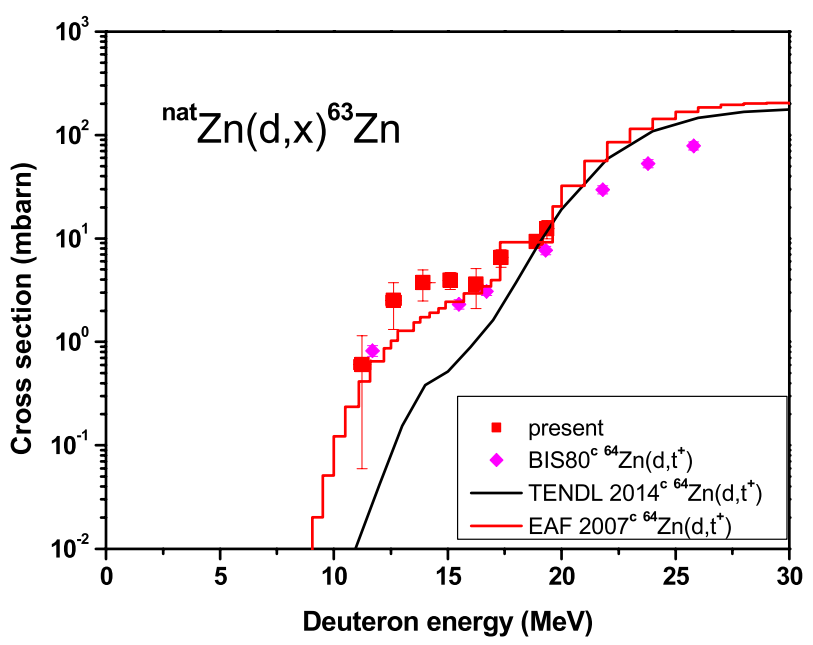

Figure 10. ${ }^{\text {nat }} \mathrm{Zn}(\mathrm{d}, \mathrm{x})^{63} \mathrm{Zn}$ production cross section vs. deuteron energy.

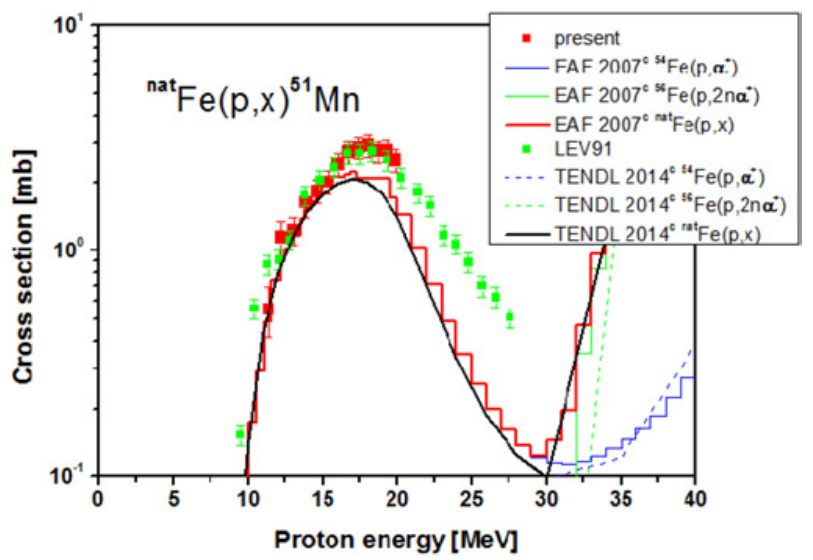

Figure 11. ${ }^{\text {nat }} \mathrm{Fe}(\mathrm{p}, \mathrm{x}){ }^{51} \mathrm{Mn}$ production cross section vs. proton energy.

${ }^{54} \mathrm{Fe}\left(\mathrm{p}, \alpha^{+}\right)$. The $\gamma$-lines from the ${ }^{51} \mathrm{Mn}$ decay are invisible for their very low intensities. For obtaining cross section of ${ }^{n a t} \mathrm{Fe}(\mathrm{p}, \mathrm{x})^{51} \mathrm{Mn}$ we used the Bateman's equation (1) (after and during irradiation). The resulting cross sections are shown in the Fig. 11. The data are in full agreement with Levkovskij [20] measuring the ${ }^{54} \mathrm{Fe}\left(\mathrm{p}, \alpha^{+}\right)$.

The data were fitted by Bateman's equation (1) (during and after irradiation) using MINUIT code to determine specific activity of mother $\left({ }^{51} \mathrm{Mn}\right) \mathrm{A}_{m}^{0}$ and daughter $\left({ }^{51} \mathrm{Cr}\right)$ 


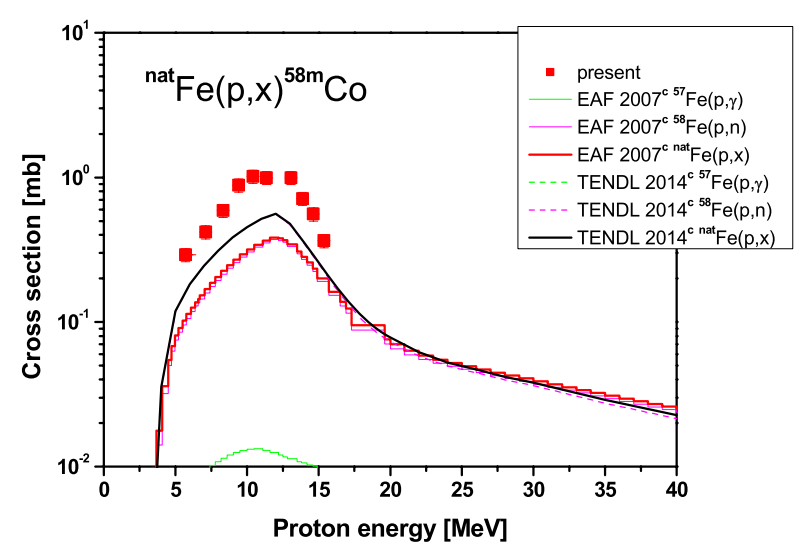

Figure 12. ${ }^{\text {nat }} \mathrm{Fe}(\mathrm{p}, \mathrm{x})^{51} \mathrm{Mn}$ production cross section vs. proton energy.

nuclei $\mathrm{A}_{g}^{0}$ at the end of irradiation

$$
A_{g}(t)=\frac{\lambda_{g}}{\lambda_{g}-\lambda_{m}} A_{m}^{0}\left(e^{-\lambda_{m} t}-e^{-\lambda_{g} t}\right)+A_{g}^{0} e^{-\lambda_{g} t}
$$

$\mathrm{A}_{\mathrm{g}}$ is the specific activity of the sample at the cooling time $\mathrm{t}, \lambda_{g}$ and $\lambda_{m}$ are the decay constants for daughter (grand) and mother isotope.

The similar procedure was used for determination of ${ }^{n a t} \mathrm{Fe}(\mathrm{p}, \mathrm{x}){ }^{58 \mathrm{~m}} \mathrm{Co}$ cross sections. The data deduced for the first time are shown at Fig. $12 .{ }^{58 \mathrm{~m}} \mathrm{Co}$ fully decays to the ground state through heavily conversed (IT) $24.9 \mathrm{keV}$ $\gamma$-transition.

\section{Outlook}

The data above $20 \mathrm{MeV}$ and short lived isotopes are planned to be measured in the future installation at SPIRAL2/NFS, that will consist of Irradiation Chamber (IC) - it will be delivered in the frame of SPIRAL2-CZ project [21] and will be coupled to Pneumatic Transfer System (PTS) - will be delivered by KIT Karlsruhe. The system will enable a transition of the samples between atmospheric pressure and vacuum (sample insertion into the beam) and also the transfer among IC, HPGe station and storage station. Activated samples will be delivered in front of the HPGe detector in short time (currently $<1 \mathrm{~min}$, transfer will be yet optimized).
The experiment was conducted on CANAM infrastructure that is supported by MEYS LM2011019. Authors also acknowledge the support of the MEYS project SPIRAL2-CZ, LM 2015076.

\section{References}

[1] M. Avrigeanu, V. Avrigeanu, A.J. Koning, Phys. Rev. C 85, 034603 (2012)

[2] http://canam.ujf.cas.cz

[3] J.F. Ziegler, J.P. Biersack, M.D. Ziegler, SRIM-The stopping and Range of Ions in Matter, computer code SRIM http: //www.srim.org/

[4] S.Y.F. Chu, L.P. Ekström, R.B. Firestone, The Lund/LBNL Nuclear Data, Seach Version 2.0, February 1999, http://nucleardata.nuclear. lu.se/toi/

[5] M.U. Khandaher, H. Haba, M. Mura, N. Otuka, NIM B 346, 8 (2015)

[6] F. Tarkanyi, S. Takacs, F. Ditroi et all., NIM B 217, 531 (2004)

[7] K. Hilgerts, T. Stoll, Y. Skakun et all., ARI 59, 343 (2003)

[8] S.J. Nassiff, H. Munzel, RRL 12, 353 (1972)

[9] J. Steyn, B.R. Meyer, ARI 24, 369 (1973)

[10] H.H. Bissem, R. Georgi, W. Scobel et all., PR C 22, 1468 (1980)

[11] L. Daraban, K. Abbas, F. Simonelli et all., ARI 66, 261 (2008)

[12] J.H. Carvier, G.A. Jones, NP 11, 400 (1959)

[13] P.P. Coetzee, M. Peisach, RCA 17, 1 (1972)

[14] N. Baron, B.L. Cohen, PR 129, 2636 (1963)

[15] D.C. Willia0ms, J.W. Irvine Jr., PR 130, 265 (1963)

[16] Cheng Xiaowu, Wang Zhenxia, Wang Zhenjie, Yang Jinging, ASI 22, 250 (1966)

[17] J.L. Gilly, G.A. Henriet, M. PreciosaAlves, P.C. Capron, PR 131, 1727 (1963)

[18] R.A. Forrest, J. Kopecky, J.Ch. Sublet, UKAEA FUS 535, UKAEA 2007

[19] A.J. Koning, D. Rochman, S.D. Mark et all., http://http.nrg.eu/pub/www/talys/ tendl2014/tendl2014.html

[20] V.N. Levkovskij, Act.Cs. By Protons and Alphas, Moscow, 1991

[21] http://www.spiral2.cz/ 